\title{
Rat small intestine absorption and membrane digestion in the process of aging
}

\author{
Sergey T. Metelsky \\ Institute of General Pathology and Pathophysiology RAMS, Moscow, Russia; s.t.metelsky@gmail.com
}

Received 26 February 2013; revised 30 March 2013; accepted 10 April 2013

Copyright (C) 2013 Sergey T. Metelsky. This is an open access article distributed under the Creative Commons Attribution License, which permits unrestricted use, distribution, and reproduction in any medium, provided the original work is properly cited.

\begin{abstract}
Recently, in our experiments, we used the shortcircuit current technique to study the kinetic constants for nutrient transporters in rat gastricintestinal tract and the thickness of the intestinal unstirred layer near the mucosa surface. It was shown that, during the process of aging, the number of nutrient monomer transporters in the small intestine increases twofold, whereas the affinity of transporters to the correspondent nutrients remains unchanged. The situation for peptides may be opposite. The layer thickness in the vicinity of the mucosa surface, measured through glucose, decreased during the process of aging. It was suggested that, in old rats, the role of the digestive volume is more important, which results in an increase of the number of nutrient monomer transporters.
\end{abstract}

Keywords: Small Intestine; Short-Circuit Current; Nutrient Absorption; Molecular Mechanisms;

Unstirred Layer; Aging

\section{INTRODUCTION}

It has long been known that aging is accompanied by changes in the functions of the GI tract, in particular, absorption and membrane digestion [1-3]. However, data on the influence of aging on the absorption of nutrients are contradictory [1,4-10]. Between all these studies, there are more differences (research methods, objects of study, the age of the animals, the localization of resected intestine, etc.) than the similarities.

One reason for these contradictions may be the fact that absorption in the intestine may be performed in several ways and each mechanism of nutrients absorption may depend on the age differently. In a quantitative sense, co-transport of $\mathrm{Na}^{+}$/glucose (SGLT1) is the most powerful and specific mechanism of absorption in the small in- testine. Sometimes, there are even contradictions in one study. Results [1] indicate, that age reduces in vitro intestinal glucose uptake in the rat, but age-associated decline in glucose uptake was not explained by alterations in SGLT1.

For nutrients from a bulk (chymus) in order to reach an intestine surface where membrane digestion and absorption occur, they must overcome a so-called unstirred layer of fluid. So, another reason for these contradictions may be the fact that in all these studies the thickness of unstirred fluid layer near the surface of the intestine, which may vary with age, was not monitored. The concept of unstirred layers distinguishes two parts in the diffusion barrier: a step that can be somehow controlled (e.g. by vigorously stirring the solution) - substrate supply from the bulk to the unstirred layer boundary - and a step that cannot be influenced by the researcher, determined through simple diffusion through the unstirred layer to membrane. The existence of unstirred layers at the biomembranes is a general but poorly studied phenomenon, which may lead to ordering adjacent water layer, resembling the formation of hydration shell about dissolved molecules and ions. During the most vigorous stirring of a solution at any, even ideally smooth, surface, there are immobile layers of water. Such layers of course are found out of and near the mucosa surface of the gastrointestinal tract. Until recently, the concept of unstirred layers has had only theoretical interest, and it was not used in clinical studies, in particular in gastroenterology. Now, clinicians have learned to successfully reduce the rate of absorption of some nutrients by giving pectin and guar gum to patients [6]. Effect of unstirred layers on the transport processes across the brush border membrane in any of the above-cited articles is not taken into account.

The third possible reason for these contradictions is that, in the large majority of studies, the conclusions about an increase or decrease in the $\mathrm{Na}^{+}$-dependent absorption of nutrients were drawn without taking into account the kinetic parameters of coupled $\mathrm{Na}^{+} /$glucose absorption. The reduction in rate of absorption may be 
caused both by the reduction of the number of corresponding transporters in the enterocyte membrane (Amax) and by the decrease of the transporter affinity to this nutrient (increase of $\mathrm{Kt}$ ).

In our study, we tried to take into account all three of the above factors. Useful tool for the resolution of the this problem is the new express procedure offered by us (the single-response method) [6] for an estimation of kinetic parameters of $\mathrm{Na}^{+}$-coupled nutrient absorption in rat intestine and thickness of an unstirred layer of a fluid on short-circuit current (SCC) response to nutrients. Preliminary results were presented in [11].

\section{MATERIALS AND METHODS}

\subsection{Experiments}

Experiments were performed on sections of me-dial intestine (spread along the contramesenteral line) from Wistar male rats not fed for $16-18 \mathrm{~h}$, with water ad libitum, by taking into consideration the following groups: young, 13 animals, age 4.5 months, weight 160 - $220 \mathrm{~g}$ and old, 5 animals, age 22 months, weight $400-550 \mathrm{~g}$.

The SCC technique modified as described in [10-12] was used. The magnitudes of SCC responses to monomer and dimer of nutrient additions to the solution, which superfused the rat intestine mucosa, were used as usual as a measure of the $\mathrm{Na}^{+}$-dependent nutrient absorption [12-15]. We used a modified Ringer's solution ( $\mathrm{pH} 7.4)$ : $80 \mathrm{mM} \mathrm{Na} \mathrm{SO}_{4}, 5.6 \mathrm{mM} \mathrm{KCl}, 2.2 \mathrm{mM} \mathrm{CaCl}_{2}, 2.05$ $\mathrm{NaHCO}_{3}$. It is known that active $\mathrm{Na}^{+}$transport does not change and that the SCC corresponds to the flow of actively transported $\mathrm{Na}^{+}$. All experiments were carried out at $24^{\circ}-26^{\circ}$. Only the serosal fluid was oxygenated.

We used nutrients from "Reanal" (Hungary) and inorganic chemical agents from "Reachim" (Russia).

\subsection{Theoretical Model}

The following theoretical model was analyzed [6]. At the time $\mathrm{t}=0$, glucose was added to the solution in such a way that, because of fast stirring, the glucose bulk concentration was constant and equal to $\mathrm{Co}$, at a distance larger than the unstirred layer thickness $(\delta)$. Glucose molecules start to diffuse through the unstirred layer to the membrane. The concentration at a distance " $x$ " from the membrane at a time " $\mathrm{t}$ " is described by the series,

$$
\begin{aligned}
C x & =C o \cdot\left[1-4 / \pi\left(\sum_{0}^{\infty}\left\{(-1)^{n}(2 n+1)\right\}\right.\right. \\
\cdot & \cos \{(\pi / 2+\pi \cdot n) \cdot x / \delta\} \\
& \left.\cdot \exp \left\{-\pi^{2} D \cdot t(2 n+1)^{2} / 4 \delta^{2}\right\}\right]
\end{aligned}
$$

where $C o$ is the bulk concentration of glucose, $C x$ is the concentration of glucose at a distance " $x$ " from the intes- tinal surface, " $n$ " are the natural numbers from 0 to infinity, $\delta$ is the unstirred layer thickness, and $D$ is the diffusion coefficient for a given nutrient.

The above expression was deduced from the solution of the diffusion equation

$$
\partial C / \partial t=D \cdot \partial^{2} C / \partial x^{2}
$$

where $C$ is the glucose concentration, $t$ is the time, " $x$ " is the distance, and $D$ is the diffusion coefficient. On the membrane surface, the nutrient concentration $(x=0)$ is equal to

$$
\begin{aligned}
C s= & C o \cdot\left[1-4 / \pi \cdot\left\{\exp \left(-\pi^{2} D \cdot t / 4 \delta^{2}\right)\right.\right. \\
& \left.\left.-1 / 3 \exp \left(-9 \pi^{2} \cdot D t / 4 \delta^{2}\right)\right\}\right]
\end{aligned}
$$

by neglecting all the terms in the series apart from the first one and by assuming that

$$
\tau=4 \delta^{2} / \pi^{2} D
$$

and by taking into account that, if $\mathrm{t}=0, \mathrm{Cs}=0$, we have

$$
C s=C o[1-\exp (-t / \tau)] \text {. }
$$

the relation between the magnitude of the SCC response to glucose and its surface concentration is not linear.

$$
\mathrm{A}=\mathrm{A}_{\max } \cdot \mathrm{Cs} /(\mathrm{Kt}+\mathrm{Cs})
$$

where $\mathrm{A}$ is the amplitude of the SCC response, Amax is the amplitude of the SCC response to infinitely high glucose concentration, and $\mathrm{Kt}$ is the glucose concentration at which the response magnitude is equal to half of the maximal response, or transport constant.

By substituting Cs in Eq.5 from Eq.4, we obtain the expression for the time dependence of the nutrient-response development

$$
\mathrm{A}=\mathrm{A}_{\max } \cdot \mathrm{Co} \cdot \exp (-\mathrm{t} / \tau) /[\mathrm{Kt}+\mathrm{Co} \cdot \exp (-\mathrm{t} / \tau)]
$$

similarly, for the time dependence of the SCC-response wash out, we have

$$
\mathrm{A}=\mathrm{A}_{\max } \cdot \mathrm{Co} \cdot \exp (-\mathrm{t} / \tau) /[\mathrm{Kt}+\mathrm{Co} \cdot \exp (-\mathrm{t} / \tau)]
$$

expression (6) at $\mathrm{t} \rightarrow \infty$ is transformed

$$
\mathrm{A}=\mathrm{A}_{\max } \cdot \mathrm{Co} /(\mathrm{Kt}+\mathrm{Co})
$$

after deriving expression (6) at the initial point of time and dividing it by expression (8), we obtain the formula for the relative initial rate of the SCC response deve- lopment

$$
\alpha=-(\mathrm{Kt}+\mathrm{Co}) /(\tau \cdot \mathrm{Kt})
$$

similarly, for the relative initial rate of the SCC-response wash out, we have

$$
\beta=-K t /(\tau \cdot(K t+C o))
$$

from expressions (8-10), we can get the final Eqs.11-13. 


$$
\begin{aligned}
& \mathrm{Kt}=\mathrm{Co} /[\sqrt{(\alpha / \beta)-1}] ; \\
& \mathrm{A}_{\max }=\mathrm{A}(\mathrm{Co}+\mathrm{Kt}) / \mathrm{Co} ; \\
& \delta=\pi / 2 \times \sqrt{\mathrm{D}} / \sqrt[4]{\alpha \beta},
\end{aligned}
$$

where $\mathrm{Co}$ is the concentration of added nutrient, $\mathrm{Kt}$ is the transport constant for nutrients, Amax is the maximal response amplitude of SCC, $\delta$ is the unstirred layer thickness, and $\mathrm{D}$ is the diffusion coefficient for a given nutrient.

The diffusion coefficients for glucose and glycine were taken to be equal to $5 \times 10^{-6} \mathrm{~cm}^{2} / \mathrm{s}$ and $4 \times 10^{-6} \mathrm{~cm}^{2} / \mathrm{s}$, respectively.

The diffusion coefficients for neutral molecules were calculated according to the formula Den $=$ Dglucose ${ }^{*}$ $\sqrt{ }$ Wglucose $/ \sqrt{W n}[16]$, and those for molecules existing in solution as ions were calculated according to the formula $\mathrm{Dn}=$ Dglycine $^{*} \sqrt{ }$ Wglycine $/ \sqrt{ } \mathrm{Wn}$, where $\mathrm{Wn}$ is the molecular weight and Dn is the diffusion coefficient for the nutrient being tested. The statistical significance of the data was assessed with the Student's t-test.

\section{RESULTS}

It turns out that the initial electrophysiological parameters of intestine preparations for young and old rats are different. Therefore, the specific electric resistances of the intestinal wall in young and old animals are significantly different, $26.0 \pm 0.8$ and $12.2 \pm 2.7 \mathrm{Ohm}^{*} \mathrm{~cm}(\mathrm{p}$ $<0.001$ ), respectively, whereas the initial potential differences on the intestinal wall for young and old rats are only slightly different, $1.77 \pm 0.36$ and $1.54 \pm 0.4 \mathrm{mV}$, respectively. The basal SCC for young and old rats is equal to $24.0 \pm 2.95$ and $23.6 \pm 3.1 \mu \mathrm{A} / \mathrm{cm}^{2}$, respectively.

The results obtained for the measurements of $\mathrm{A}, \alpha$, and $\beta$ are presented in Table 1. For old animals, the amplitude of the SCC response to nutrients tends to be larger than that for young animals, and for L-leucine, the difference is significant $(\mathrm{p}<0.02)$.

For old rats, the relative initial rate of the response development $\alpha$ is maximal for glucose, and for young ones, it is maximal for L-leucine. The relative initial rate of washout of the SCC response $\beta$ to glucose is maximal both for young and old animals. The parameters $\alpha$ and $\beta$ vary less (root-sum-square uncertainty/ arithmetic mean) from experiment to experiment than the values of the responses (A).

According to data gathered in experiments on rats [810], the maximal rates of absorption (Amax) for L-alanine and L-leucine increase considerably with age (Table 2).

As this occurs, according to Penzes [8], Kt for alanine increases from 7.2 to $35.5 \mathrm{mM}$ with aging. According

\begin{tabular}{|c|c|c|c|}
\hline $\begin{array}{c}\text { Nutrient, } \\
\text { Concentration, } \\
\mathrm{mM}\end{array}$ & SCC response amplitude $\mu \mathrm{A} / \mathrm{cm}^{2}$ & $\begin{array}{c}\text { Relative } \\
\text { initial rate } \\
\text { of } \mathrm{SCC} \text { development, } \\
\alpha \cdot 10^{2} \text { in } 1 / \mathrm{s} \\
\end{array}$ & $\begin{array}{c}\text { Relative } \\
\text { initial rate } \\
\text { of } \mathrm{SCC} \text { washout, } \\
\beta \cdot 10^{2} \text { in } 1 / \mathrm{s} \\
\end{array}$ \\
\hline \multicolumn{4}{|c|}{ Old animals } \\
\hline D-glucose, $10 \mathrm{mM}$ & $45.2 \pm 12.1(5)$ & $3.17 \pm 0.63(5)$ & $0.96 \pm 0.09(5)$ \\
\hline Maltose, $5 \mathrm{mM}$ & $44.7 \pm 14.2(5)$ & $2.60 \pm 0.47(5)$ & $0.73 \pm 0.14(5)$ \\
\hline L-Alanine, $10 \mathrm{mM}$ & $38.7 \pm 9.5(5)$ & $1.42 \pm 0.19(5)$ & $0.55 \pm 0.09(5)$ \\
\hline L-Leucine, $10 \mathrm{mM}^{*}$ & $22.0 \pm 2.66(5)$ & $1.97 \pm 0.30(5)$ & $0.51 \pm 0.09(5)$ \\
\hline Gly-L $\alpha$-Ala, 2 mM & $25.6 \pm 8.4(5)$ & $1.16 \pm 0.23(5)$ & $0.59 \pm 0.14(5)$ \\
\hline \multicolumn{4}{|c|}{ Young animals } \\
\hline D-glucose, $10 \mathrm{mM}$ & $20.0 \pm 3.8(13)$ & $2.13 \pm 0.17(13)$ & $0.83 \pm 0.11(13)$ \\
\hline Maltose, $5 \mathrm{mM}$ & $22.7 \pm 4.0(13)$ & $2.09 \pm 0.19(13)$ & $0.80 \pm 0.12(13)$ \\
\hline Sucrose, $10 \mathrm{mM}$ & $17.1 \pm 3.1(13)$ & $1.34 \pm 0.16(13)$ & $0.82 \pm 0.11(13)$ \\
\hline L-Alanine, $10 \mathrm{mM}$ & $18.5 \pm 3.6(13)$ & $1.72 \pm 0.22(13)$ & $0.63 \pm 0.07(13)$ \\
\hline L-Leucine, $10 \mathrm{mM}^{*}$ & $12.6 \pm 1.98(13)$ & $2.47 \pm 0.27(13)$ & $0.59 \pm 0.06(13)$ \\
\hline Gly-L $\alpha$-Ala, 2 mM & $14.7 \pm 2.35(13)$ & $1.45 \pm 0.15(13)$ & $0.75 \pm 0.09$ \\
\hline
\end{tabular}

Table 1. Characteristic of short-circuit current $(\mathrm{SCC})(\mathrm{A}, \alpha, \beta)$ responses to nutrient addition to mucosa solution across the small intestine wall of young and old rats.

Here and in Tables 2-4, the number of experiments is indicated in parentheses.

*Data differ significantly. 
to our data for young and old rats, these parameters are equal to 16.8 and $17.5 \mathrm{mM}$, respectively (i.e., they do not vary). The maximal and minimal values of $\mathrm{Kt}$ for leucine in [9] are equal to 18.2 and $2.6 \mathrm{mM}$, respectively. According to our data, the magnitudes of $\mathrm{Kt}$ for leucine are also in the same range- 10.4 and $11.6 \mathrm{mM}$. However, although $\mathrm{Kt}$ for the indicated amino acids in Penzes study [9] increases considerably with age, $\mathrm{Kt}$ for alanine and leucine remains constant in our study (Table 3).

The maximal values of the response (Amax) to glucose, similarly to that to amino acids, are considerably higher for old rats than those for young rats (Table 2). This is in agreement with data presented in [17]. In this study, sucrase and isomaltase activities significantly increased during aging in the duodenum and jejunum, and lactase and amino peptidase activities increased significantly in senescent animals. But Kt for glucose varies only slightly with aging (Table 3 ).

Unlike for monomers, upon absorption of dimmers (maltose and glycyl-L $\alpha$-alanine), a significant increase in Amax with aging is not observed. The affinity of en- zyme-transport ensemble for glycyl-L $\alpha$-alanine tends to decline, and for maltose, it tends to increase. The greatest values of Amax and $\mathrm{Kt}$ for sucrose (for young rats) are $91.3 \mu \mathrm{A} / \mathrm{cm}^{2}$ and $41.8 \mathrm{mM}$, respectively.

Data on the effect of aging on the thickness of the $\mathrm{u}$ nstirred layer of a fluid near the intestine surface are also contradictory. In our experiments (Table 4), according to [4], the layer thickness determined by glucose decreases with age.

On the contrary, the layer thickness determined with amino acids and dipeptide tends to increase with age, which is in agreement with results presented in [18]. In another study [9], the layer thickness decreases from 318 to $268 \mu \mathrm{m}$ with age. Our values (Table 4) are in good agreement with those given above.

\section{DISCUSSION}

The electric resistance of the intestinal wall decreases more than twice with age. The major contribution to the electric resistance of the intestinal wall comes from the resistance of the epithelial sheet $[6,19]$. Because the re-

Table 2. Calculated maximal values of short-circuit current responses (Amax) to nutrient addition to mucosa solution across the the small intestine wall of young and old rats.

\begin{tabular}{|c|c|c|c|c|c|c|}
\hline \multirow{2}{*}{ Rat age } & \multicolumn{5}{|c|}{$\mathrm{Amax}, \mu \mathrm{A} / \mathrm{cm}^{2}$} & \multirow[b]{2}{*}{$\begin{array}{c}\text { Gly-L } \alpha \text {-Ala } \\
2 \mathrm{mM}\end{array}$} \\
\hline & $\begin{array}{c}\text { D-Glucose, } \\
10 \mathrm{mM}\end{array}$ & $\begin{array}{l}\text { Maltose, } \\
5 \mathrm{mM}\end{array}$ & $\begin{array}{c}\text { Sucrose, } \\
10 \mathrm{mM}\end{array}$ & $\begin{array}{c}\text { L-Alanine, } \\
10 \mathrm{mM}\end{array}$ & $\begin{array}{c}\text { L-Leucine, } \\
10 \mathrm{mM}\end{array}$ & \\
\hline Old & $\begin{array}{c}101.0 \pm 15.5 \\
(5)\end{array}$ & $\begin{array}{c}99.0 \pm 28.0 \\
(5)\end{array}$ & & $\begin{array}{c}103.0 \pm 24.0 \\
(5)\end{array}$ & $\begin{array}{c}45.5 \pm 7.5 \\
(5)\end{array}$ & $\begin{array}{c}82.0 \pm 15.5 \\
(5)\end{array}$ \\
\hline \multirow[t]{2}{*}{ Young } & $\begin{array}{c}51.1 \pm 9.7 \\
\quad(13)\end{array}$ & $\begin{array}{c}62.4 \pm 14.3 \\
(13)\end{array}$ & $\begin{array}{c}91.3 \pm 19.9 \\
(13)\end{array}$ & $\begin{array}{c}48.4 \pm 8.9 \\
(13)\end{array}$ & $\begin{array}{c}24.6 \pm 3.6 \\
(13)\end{array}$ & $\begin{array}{c}60.8 \pm 10.1 \\
(13)\end{array}$ \\
\hline & & $p<0.02$ & & $p<0.05$ & $p<0.05$ & \\
\hline
\end{tabular}

Table 3. Transport constants (Kt) for nutrients in old ( 22 months) and young ( 4.5 months) rats.

\begin{tabular}{ccccccc}
\hline Kt, mM & D-Glucose $10 \mathrm{mM}$ & $\begin{array}{c}\text { Maltose } \\
5 \mathrm{mM}\end{array}$ & $\begin{array}{c}\text { Sucrose } \\
10 \mathrm{mM}\end{array}$ & $\begin{array}{c}\text { L-Alanine } \\
10 \mathrm{mM}\end{array}$ & $\begin{array}{c}\text { L-Leucine } \\
10 \mathrm{mM}\end{array}$ & $\begin{array}{c}\text { Gly-L }{ }_{\alpha} \text {-Ala } \\
2 \mathrm{mM}\end{array}$ \\
\hline \multirow{2}{*}{ Old rats } & $14.9 \pm 2.8(5)$ & $12.7 \pm 2.3(5)$ & & $17.5 \pm 2.5(5)$ & $10.4 \pm 0.9(5)$ & $13.7 \pm 3.5(5)$ \\
Young rats & $17.6 \pm 2.9(13)$ & $16.6 \pm 6.2(13)$ & $41.8 \pm 5.9(13)$ & $\begin{array}{c}16.8 \pm 1.8 \\
(13)\end{array}$ & $\begin{array}{c}11.6 \pm 1.8 \\
(13)\end{array}$ & $\begin{array}{c}6.2 \pm 1.0 \\
(13)\end{array}$ \\
\hline
\end{tabular}

Table 4. Unstirred liquid layer thickness $(\delta)$ in the vicinity of the intestine mucosa surface of young and old rats, calculated from the short-circuit current responses to nutrient addition.

\begin{tabular}{|c|c|c|c|c|c|c|}
\hline \multirow{2}{*}{ Rat age } & \multicolumn{6}{|c|}{$\delta, \mu \mathrm{m}$} \\
\hline & D-Glucose, $10 \mathrm{mM}$ & $\begin{array}{l}\text { Maltose, } \\
5 \mathrm{mM}\end{array}$ & $\begin{array}{l}\text { Sucrose, } \\
10 \mathrm{mM}\end{array}$ & L-Alanine, $10 \mathrm{mM}$ & L-Leucine, $10 \mathrm{mM}$ & $\begin{array}{c}\text { Gly-L } \alpha \text {-Ala, } \\
2 \mathrm{mM}\end{array}$ \\
\hline Old & $\begin{array}{c}273 \pm 13 \\
(5)\end{array}$ & $\begin{array}{c}260 \pm 22 \\
(5)\end{array}$ & & $\begin{array}{c}310 \pm 21 \\
(5)\end{array}$ & $\begin{array}{c}265 \pm 18 \\
(5)\end{array}$ & $\begin{array}{c}293 \pm 28 \\
(5)\end{array}$ \\
\hline Young & $\begin{array}{c}324 \pm 15 \\
(13)\end{array}$ & $263 \pm 20(13)$ & $315 \pm 21(13)$ & $\begin{array}{c}287 \pm 15 \\
(13)\end{array}$ & $\begin{array}{c}240 \pm 12 \\
(13)\end{array}$ & $\begin{array}{c}258 \pm 17 \\
(13)\end{array}$ \\
\hline & $p<0.02$ & & & & & \\
\hline
\end{tabular}


sistance of epithelial tissues is determined mainly by the resistance of its tight junctions and the height of the villi does not vary with age $[4,10]$, we reach the conclusion that, during the process aging, the tight junctions between enterocytes become more permeable [2,20].

The thickness of the unstirred layer is commensurate with the height of the villi [6]. Data measured for rats have been published showing that this parameter increases with age $[5,7,10]$, decreases $[4,10]$, or remains constant [10]. As it follows from our study, L determined by glucose significantly decreases, L determined by maltose tends to decrease, and L determined by amino acids and dipeptide tends to increase with age.

Previously $[11,15]$, it was shown that the transporter distribution along the villi is non-uniform and may differ as a function of the solute concentration and may differ intrinsically for different nutrients; such arrangement of transporters along the villi is the first demonstration of the new hitherto unknown principle of space-time organization of intestinal absorption and membrane digestion. Because the height of the villi in a rat intestine does not change with age [5] or decreases [17,21], the unstirred-layer thickness measurement maybe used to study the topography of nutrient transporters. On this basis, the space-time organization of intestinal absorption and membrane digestion with aging is changed.

The ability of the intestine to absorb nutrient monomers (glucose, amino acids) with aging increases by approximately $100 \%$. Like in [22], these findings suggest that impaired carbohydrate absorption due to aging is related to factors other than diminished mucosal glucose uptake. The ability to utilize dimers (maltose, dipeptide) from the intestinal lumen tends to increase by $30 \%-50 \%$ (Table 3), and these facts are in agreement with data showing that activities of sucrase, isomaltase, and aminopeptidase increase significantly during aging in the jejunum [17]. The results, when combined with those of previous studies, suggest that, in old animals, the increased level of intestinal hydrolase activities may be the consequence of prolonged cellular maturation along the villi in the proximal intestine and of adaptation to increased concentrations of intraluminal substrates in the distal intestine [17].

This points to the fact that, in the enterocytes membrane of old animals, the number of transporters for each of the analyzed nutrients sharply increases. As this occurs, the affinity of transporters for glucose, maltose, alanine, and leucine practically does not change with age (Table 3).

Although for old rats the coefficient of correlation $r_{\text {corr }}$ between the transport constant $\mathrm{Kt}$ and the maximal response Amax for all five nutrients is equal to 0.796, for young animals, there is no such correlation $\left(r_{\text {corr }}=0.022\right)$. Hence, the fewer transporters for a given nutrient there are in the enterocyte membrane of an old animal, the larger their affinity to this nutrient. Perhaps, that observation reflects the animal's adaptation to aging.

Thus, in a rat small intestine, there are essential functional changes with aging. The ability to absorb nutrient monomers increases, and that to absorb dimers tends to increase because of a rise in the number of transporters. Data gathered in our experiments performed by using glucose are consistent with [22]. Because animals in both experimental groups obtained the same ration, this means that an old rat adapts for the raised concentration of monomers in the intestinal lumen. It has long been known that monomers may be formed at cavital digestion.

Hence, additional transporters in a brush-border membrane appear, apparently, in response to an increase in the level of cavital digestion, resulting in an increase in nutrient monomer concentration in the intestinal lumen. Upon aging, the ratio between cavital and membrane digestion shifts in favor of the former, although, at the same time, the membrane digestion tends to increase (disaccharide and dipeptide).

\section{CONCLUSION}

By the new express technique offered by us (the single-response method) we have studied the effect of age of rats (4.5 and 22 months) on kinetic parameters of $\mathrm{Na}^{+}$coupled nutrient intestinal absorption and thickness of an unstirred layer for five nutrients: as monomers-glucose, alanine and leucine and dimers-maltose, sucrose, and the dipeptide glycyl-L $\alpha$-alanine. The ability to absorb nutrient monomers-Amax (the maximal response amplitude of SCC) increases, and that to absorb nutrients dimers tends to increase because of a rise in the number of transporters.

In this case, the transport constant for nutrients $\mathrm{Kt}$ does not change. This fact indicates that the functional properties of the studied nutrient transporters in aging are not changed.

The thickness of the unstirred layer $\delta$ determined by glucose significantly decreases, $\delta$ determined by maltose tends to decrease, and $\delta$ determined by amino acids and a dipeptide tends to increase with age.

\section{REFERENCES}

[1] Drozdowski, L., Woudstra, T., Wild, G., Clandindin, M.T. and Thomson, A.B. (2003) The age-associated decline in the intestinal uptake of glucose is not accompanied by changes in the mRNA or protein abundance of SGLT1. Mechanism of Ageing and Development, 124, 1035-1045. doi:10.1016/j.mad.2003.07.003

[2] Drozdowski, L. and Tomson A.B.R. (2006) Aging and the intestine. World Journal of Gastroenterology, 12, 75787584. 
[3] Ugolev, A. and Timofeeva, N. (1989) Enzymatic adaptation of digestive system. In: Ugolev, A.M., Ed., Membrane digestion. New Facts and Concepts. MIR Publishers, Moscow, 173-183.

[4] Hollander, D. and Dadufaza, V.D. (1983) Aging: Its influence on the unstirred water layer thickness, surface area, and resistance in the unanesthetized rat. Canadian Journal of Physiology and Pharmacology, 61, 1501-1508. doi:10.1139/y83-215

[5] Holt, P.R., Pascal, D.R. and Kotler, D.P. (1984) Effect of aging upon small intestine structure in the Fisher rat. Journal of Gasrtoenterology, 39, 642-647.

[6] Metelsky, S.T. (2011) Transport phenomena and membrane digestion in small intestinal mucosa. An electrophysiological approach. Pensoft, Sofia.

[7] Navab, F. and Winter, G.G. (1988) Effect of aging on intestinal absorption of aromatic amino acids in vitro in the rat. American Journal of Physiology, 254, G630-G636.

[8] Penzes, L. (1974) Further data on the age-dependent intestinal absorption of dibasic amino acids. Experimental Gerontology, 9, 259-262. doi:10.1016/0531-5565(74)90022-9

[9] Penzes, L. (1974) Intestinal absorption of glycine, L-alanine, L-leucine in the old rat. Experimental Gerontology, 9, 245-252. doi:10.1016/0531-5565(74)90020-5

[10] Penzes, L. and Boross, M. (1974) Intestinal absorption of some heterocyclic and aromatic amino acids from the aging gut. Experimental Gerontology, 9, 253-258. doi:10.1016/0531-5565(74)90021-7

[11] Metelsky, S.T. (2008) Effect of age on intestinal absorption and membrane digestion in the rat. The Journal of Physiology and Biochemistry, 64, 45.

[12] Alexander, A.N. and Carey, H.V. (2001) Involvement of PI3-kinase in IGE-1 stimulation of jejunal $\mathrm{Na}^{+}, \mathrm{K}^{+}$-ATPase activity and nutrient absorption. AJP-Gastrointest and Liver Physiology, 280, G222-G228.

[13] Green, B.T., Bunett, N.W., Kulkarni-Narla, F.A, Steinhoff, M. and Brown, D.R. (2000) Intestinal type 2 proteinaseactivated receptors: Expression in opioid-sensitive secre- tomotor neural circuit that mediate epithelial ion transport. Journal of Pharmacology and Experimental Therapeutics, 295, 410-416.

[14] Kroesen, A.J., Stockmann, M., Ransco, M., Schulzke, J. D., Fromm, M. and Buhr, H.J. (2002) Impairment of epithelial transport but not barrier function in idiopathic pouchitis after ulcerative colitis. Gut, 50, 821-826. doi:10.1136/gut.50.6.821

[15] Metelsky, S.T. (2007) Dependence of the thickness of the unstirred layer at the intestinal mucosa on nutrient concentration. Biophysics, 52, 423-425. doi:10.1134/S0006350907040124

[16] Kotyk, A. and Janacek, K. (1977) Membrane transport an interdisciplinary approach. Biomembranes, 9, 3-348.

[17] Raul, F., Gosse, F., Doffoel, M., Darmenton, P. and Wessely, J.Y. (1988) Age related increase of brush border enzyme activities along the small intestine. Gut, 29, 15571563. doi:10.1136/gut.29.11.1557

[18] Thomson, A.B.R. (1979) Unstirred water layer and agedependent changes in rabbit jejunal D-glucose transport. American Journal of Physiology, 236, E685-E691.

[19] Ugolev, A.M., Metelsky, S.T., Gurman, E.G. and Mamatakhunov, A.I. (2001) Deepithelized preparation of rat small intestine-Transport properties.

[20] Weber, M.P., Martin, L.J., Dumon, H.J., Biourge, V.C. and Nguyen, P.G. (2002) Influence of age and body size on intestinal permeability and absorption in healthy dogs. American Journal of Veterinary Research, 63, 1323-1328. doi:10.2460/ajvr.2002.63.1323

[21] Keelan, M., Walker, K. and Thomson, A.B. (1985) Intestinal morphology, marker enzymes and lipid content of brush border membranes from rabbit jejunum and ileum: Effect of aging. Mechanism of Ageing and Development, 31, 49-68. doi:10.1016/0047-6374(85)90026-0

[22] Thompson, J.S., Crouse, D.A., Mann, S.L., Saxena, S.K. and Sharp, J.G. (1988) Intestinal glucose uptake is increased in aged mice. Mechanism of Ageing and Development, 46, 135-143. doi:10.1016/0047-6374(88)90121-2 